\title{
Article \\ A Guidance for Blockchain-Based Digital Transition in Supply Chains
}

\author{
Fabio Della Valle *(D) and Miquel Oliver
}

check for updates

Citation: Della Valle, F.; Oliver, M. A Guidance for Blockchain-Based Digital Transition in Supply Chains. Appl. Sci. 2021, 11, 6523. https:// doi.org/10.3390/app11146523

Academic Editor: Gianluca Lax

Received: 31 May 2021

Accepted: 7 July 2021

Published: 15 July 2021

Publisher's Note: MDPI stays neutral with regard to jurisdictional claims in published maps and institutional affiliations.

Copyright: (c) 2021 by the authors. Licensee MDPI, Basel, Switzerland. This article is an open access article distributed under the terms and conditions of the Creative Commons Attribution (CC BY) license (https:/ / creativecommons.org/licenses/by/ $4.0 /)$.
Engineering Department of Information and Communication Technologies, University Pompeu Fabra, 08018 Barcelona, Spain; miquel.oliver@upf.edu

* Correspondence: fabio.dellavalle@upf.edu

Featured Application: Results of this study may support the design phases of digital transition in blockchain-based supply chains.

Abstract: Blockchains play a crucial role in the digitalization of future supply chains (SCs). In this study, we analyzed the major influences that blockchain-based digital business strategies may play in SC operations. We conducted 18 interviews with international experts from different sectors and analyzed the collected data using the grounded theory approach, identifying four major categories. A set of three matrices is presented to address those elements that may support digital transition procedures in SCs: (1) value of trust and automation, (2) transformative role for operations, and (3) digital business strategy identification. As an additional result, a reference framework was identified for the evaluation and detection of those aspects to be taken into consideration during blockchain adoption in SCs. For use as a guide, this result comprises 22 recommendations and was framed in four progressive steps as follows: (1) identify, (2) assess, (3) design, and (4) assure.

Keywords: blockchain; decentralized applications; digitalization; strategy; supply chain

\section{Introduction}

As an emerging technology, blockchain is still in its infancy in business applications [1-3]. However, in the last few years, the supply chain (SC) has been considered one of the fields where blockchain technologies have been implemented with higher impact $[4,5]$. According to Saberi et al. [6], blockchain is a driver for digitalization in the SC, but the resulting improvements in performance are difficult to predict [7]. The implementation of blockchain-based SCs has been largely explored for the traceability and transparency of products. Traceability and transparency, along with the development of an advanced level of trust, were identified as the main drivers for blockchain adoption [6-9].

Nevertheless, there is a lack of experience, knowledge, and understanding regarding blockchain [6]. Moreover, according to Courcelas et al. [10], there is a lack of education programs focusing on blockchain and related skills. Thus, more education and research are needed in this area for a better understanding of the impact of this technology and its acquisition procedures. Additionally, as a software-based technology, blockchain should be addressed in digitalization strategies and goals [11], but thus far, its impacts and digital transitions are unclear [12]. However, information management and trust were identified as factors for the implementation of blockchain-based SCs [13]. Nonetheless, further research is necessary to explore how SC operations may be impacted with sufficient benefits, the reward maximized, and a higher level of efficiency and effectiveness assured [7,14]. For this purpose, digitalization and digital transition may play an essential role [5,15]. Thus, this research aims to fill these research gaps, provide an insight into the body of knowledge in this area, and explore which elements might play a relevant role for the identification of those digital strategies that may assure operational efficiency and effectiveness in the SC sector. 
Therefore, this study answers the following research question (RQ): Which are the elements for designing blockchain-based digital strategies that might foster a reliable re-engineering in SC operations?

Following an analysis of 18 interviews with international experts, and by applying the grounded theory methodology, we were able to analyze the data obtained to address the above-mentioned RQ and contribute to the body of knowledge in this research area.

As main contributions, this explorative research provides the following outcomes: (I) a summary of key findings of previous research and a taxonomy of existing work; (II) a presentation of findings emerged from the experts interviewed, divided into four major categories; and (III) a set of elements and recommendations presented as matrices and tables for a suitable adoption in SC applications.

The uniqueness of this explorative research is that it merges a qualitative approach based on interviewing experts with an exhaustive and solid literature review to create a scientific contribution that aims to answer the research question. As an interdisciplinary work, it follows previous research in the blockchain field [3,5,6,11,13,15].

The remainder of this paper is structured as follows: Section 2 presents a literature review of the most relevant research works for the study and a taxonomy, Section 3 details the grounded theory methodology and analysis of the collected data, Section 4 elaborates on the findings of the analysis, Section 5 offers a discussion and the research contributions, and Section 6 presents the conclusions.

\section{Literature Review and Taxonomy}

This section reviews the most relevant previous works on blockchain-based SCs and digitalization. Thus, this work is based on a solid literature review that creates the needed state of the art to design this explorative research centered on expert interviews. A taxonomy is presented at the end of this section.

\subsection{Literature Review}

In accordance with B. Kitchenham [16], we identified and designed a process for conducting the literature review in three main phases: (I) planning the review, (II) conducting the review, and (III) reporting the review. Moreover, a research question and a procedure were defined for the study. Conducting the review, the databases/platforms used for the exploration were the following: Scopus, Google Scholar, IEEE Xplore, and Taylor and Francis Online. During the online search, several key works were applied in those platforms. The review conducted was mainly aimed to explore blockchain-based supply chains and their correlation with digitalization. Thus, some examples of the keyworks and acronyms that have been used for the exploration are related with blockchain (BT), systematic literature review (SLR), digital and digitization, SC and supply chain management (SCM), and other words connected with the study. Therefore, mixing these words, we collected several research works from the databases used.

At this stage, selecting a timeframe from 2019 to 2021 and applying the first screening by abstracts, we selected the papers for the next stage. Consequently, the literature analysis of these selected research works was performed, and the main findings were collected as memos and notes. Hence, keeping in mind the aims of the study and the research question, we extracted relevant data and presented them in a concise form. Additionally, all bibliographies of these selected papers were analyzed, and a second iteration of literature review performed. This supported the identification of relevant previous works from a wider timeframe and consolidated the body of knowledge for these research lines.

Therefore, Table 1 summarizes findings of the most relevant previous studies linked to this explorative research. Findings in Table 1 were used to enrich expert interviews' outcomes in an attempt to bridge the gap in the existing body of knowledge and provide a final comprehensive contribution (see Section 5). 
Table 1. Literature review.

\begin{tabular}{cc}
\hline Articles & Focus \\
\hline Chang et al. [1] & $\begin{array}{c}\text { Benefits of blockchain-based supply } \\
\text { chain (SC) }\end{array}$
\end{tabular}

(1) streamline and harmonize information and process flow across supply chain networks; (2) improve data quality; (3) support the timely analysis of supply chain risks; (4) develop efficient business processes between governments and global supply chain stakeholders

(i) motivators: (1) pressures; (2) drivers

Saberi et al. [3] and Motivators and barriers for Kouhizadeh et al. [17] blockchain-based SC (ii) barriers: (1) organizational barriers; (2) supply chain-related barriers; (3) technological barriers; (4) external barriers

\begin{tabular}{cc} 
Kayikci et al. [4] & $\begin{array}{c}\text { Interaction effects of blockchain to } \\
\text { strengthen relationships }\end{array}$ \\
\hline Fosso Wamba et al. [5] & Blockchain diffusion stages \\
\hline Bai et al. [7] & SC transparency types \\
\hline Hastig et al. [8] & $\begin{array}{c}\text { Critical success factors for } \\
\text { blockchain-based SC }\end{array}$ \\
\hline Kittipanya-Ngam et al. [9] & Dimensions to underpin the SC \\
digitalization
\end{tabular}

Seyedghorban et al. [12] Five paths for digitalization in SC
At a micro level (people, process, technology, and performance), blockchain technology will ensure: (1) non-manipulation of data, (2) transparency, (3) security, and (4) collaboration among the stakeholders

(1) intention, (2) adoption, and (3) routinization

(i) range of transparency; (ii) product transparency; (iii) participant transparency

(1) companies' capabilities; (2) collaboration; (3) technology readiness; (4) supply chain practices; (5) leadership; (6) governance of the traceability efforts

(1) efficiency, (2) transparency and traceability, (3) environmental and social impacts, (4) legal liability, and (5) e-market/supply accessibility

(1) data science-enabled SC management, (2) SC agility, (3) humanizing manufacturing through digital manufacturing strategy, (4) omni-channel, and (5) resource-based view and beyond

(1) distributed and synchronized across networks; (2) use of Characteristics of blockchain-based
Cole al. [18]

smart contracts; (3) based on peer-to-peer networks; (4) immutability of data

(i) strengths: (1) visibility; (2) aggregation; (3) validation; (4) automation; (5) resiliency

(ii) weaknesses: (1) lack of privacy; (2) lack of

Babich et al. [19] $\quad \begin{aligned} & \text { Strengths and weaknesses of } \\ & \text { blockchain-based operations }\end{aligned}$

Ho et al. [20] SC risks

Büyüközkan et al. [21] SC components for digitalization

Birkel et al. [22] Risks for IoT in SC standardization; (3) garbage in, garbage out; (4) black box effect; (5) inefficiency

(1) macro risk; (2) demand risk; (3) manufacturing risk; (4) supply risk; (5) infrastructural risk

(i) digitalization: (1) strategy; (2) organization and culture; (3) operations; (4) products and services; (5) digital

(ii) technology implementation: (6) project management; (7)

human and technology relationship; (8) formation of technology infrastructure; (9) technology enablers

(iii) supply chain management: (10) integration; (11) automation; (12) reconfiguration; (13) analytics; (14) process

(i) environmental risk: (1) economic; (2) social; (3) technological; (4) political

(ii) network-related risk: (5) relational aspects; (6) identification of trust

(iii) organizational risks: (7) internal aspects; (8) high implementation barriers customer experience 
Table 1. Cont.

\begin{tabular}{|c|c|c|}
\hline Articles & Focus & Key Findings \\
\hline Bharadwaj et al. [23] & Digital business strategy & $\begin{array}{c}\text { Themes (4S Model) of digital business strategy: (1) scope } \\
\text { (effectiveness), (2) scale (profitability), (3) speed (time), and } \\
\text { (4) sources of business value creation and capture } \\
\text { (robustness) }\end{array}$ \\
\hline Brown et al. [24] & Digital transformation & $\begin{array}{l}\text { Theory (4E Model) of digitalization: (1) expectations (people, } \\
\text { communities, and clients), (2) execution (organization and } \\
\text { delivery), (3) ecosystem (platforms and interfaces), and (4) } \\
\text { enablers (infrastructure and technology) }\end{array}$ \\
\hline Nandi et al. [25] & $\begin{array}{l}\text { Capabilities and performances of } \\
\text { supply chain (SC) }\end{array}$ & $\begin{array}{l}\text { (i) SC capabilities: (1) information sharing, (2) coordination, } \\
\text { (3) integration, (4) collaboration } \\
\text { (ii) SC performances: (1) quality, (2) process improvement, } \\
\text { (3) flexibility, (4) cost reduction, (5) process time reduction }\end{array}$ \\
\hline WEF [26] & Blockchain key issues & $\begin{array}{c}\text { (1) blockchain policy, regulation, and law; (2) tokenization } \\
\text { and digital assets; (3) blockchain security and } \\
\text { interoperability; (4) smart contracts and automation; (5) } \\
\text { blockchain and digital identity; (6) decentralized } \\
\text { governance and new models; (7) blockchain and leveraging } \\
\text { data }\end{array}$ \\
\hline Fosso Wamba et al. [27] & Benefits of blockchain in business & $\begin{array}{c}\text { (1) operational; (2) managerial; (3) strategic; (4) } \\
\text { infrastructure }\end{array}$ \\
\hline Wang et al. [28] & $\begin{array}{l}\text { Design phases for blockchain-based } \\
\text { SC }\end{array}$ & $\begin{array}{l}\text { (1) definition of the best entry point; (2) identification of } \\
\text { areas where blockchain adds value to all stakeholders; (3) } \\
\text { determination of a minimal number of actors and core } \\
\text { members; (4) network orchestration and co-creation; (5) } \\
\text { on-chain and off-chain governance; (6) protection of } \\
\text { sensitive data; (7) careful consideration for sharing on-chain } \\
\text { data; (8) establishment of legal and regulatory } \\
\text { documentation }\end{array}$ \\
\hline
\end{tabular}

Accordingly, in the next part of this section, the literature review used analyses the several works related to blockchain, SC, and the integration thereof. The selected literature for blockchain-based SCs review is the following [1-11,13-15,17-19,25-32]. The SC management were also researched in different scenarios where digitalization and digital business strategies were considered as crucial factors. Thus, the selected literature for digital strategies and SC digitalization is the following [12,20-24,33-37].

\subsubsection{Blockchain-Based SC}

Although the blockchain technology has its origins in the finance sector [29], it has found a proper space for application in the SC. Blockchain is in its infancy [18]; however, blockchain is described as a 'trust machine', leading to a data-driven economy [30]. As a distributed database, the blockchain functions may level the value chain [31].

According to Koh et al. [29], more research is needed in multimodal transport and logistics environments. In these sectors, blockchain may be a tool for enhancing the system efficiency [32] and is defined as a driver for digitalization in the SC [3].

The implementation of blockchain in operations and SC management (SCM) [18] is related to the fields of information and automation [19]. Assuming that blockchain is a tool for information management [2], it mitigates the information asymmetry; reduces the bullwhip effect; supports a lean, agile, and total-quality management and just-in-time principles; and collaborates to enhance the internal and external SCM [19,29].

The challenge for future developments is blockchain interoperability [1]. Thus, for blockchain development, organizations should address it within the existing problems they have in their business [33]. However, a blockchain-based approach is cost-intensive in terms of storage and computational requirements, and as computational costs have 
become a significant burden [34], new developments in alternative consensus protocols are required.

According to Ho et al. [20], SC risk (SCR) is defined as 'the likelihood and impact of unexpected macro-and/or micro-level events or conditions that adversely influence any part of a supply chain leading to operational, tactical, or strategic level failures or irregularities'. Ho et al. [20] designed a framework to define risks and easily identify whether they are internal or external risks (demand, manufacturing, supply), macro or micro risks (degree of impacts), or risks related to different types of flow (information, transportation, financial).

According to Büyüközkan et al. [21], the digital SC (DSC) is defined as 'an intelligent best-fit technological system that is based on the capability of massive data disposal and excellent cooperation and communication for digital hardware, software, and networks to support and synchronize interaction between organizations by making services more valuable, accessible, and affordable with consistent, agile, and effective outcomes'. Consequently, the features of a fully deployed DSC are speed, flexibility, global connectivity, real-time inventory, intelligence, transparency, scalability, innovation, proactivity, and eco-friendliness [21].

In this instance, the decision support methods in SCM domains are required to be proactive and reactive simultaneously [35]. This can be achieved with robustness reserves (proactive: risk mitigation inventory, capacity flexibility, backup facilities and channels) and the speed and scale of recovery actions (reactive: parametric recovery, process recovery, and structural recovery).

Ben-Daya et al. [36] explored the role of the internet of things (IoT) and its impact on SCM processes and applications. The IoT for SCM is still in its early stage of development; in contrast, the IoT for logistics and manufacturing is more advanced [36]. The IoT in blockchain-based solutions validates the identities of individuals and assets. Thus, blockchain can be used in an SC to know who is performing what actions, and these features facilitate a valid and effective measurement of outcomes and performance of key SCM processes [14].

According to Kshetri [37], this combination offers an enhancement of security, given that if the blockchain updates of one IoT device are breached, the system rejects it, and if the network size increases exponentially, a blockchain structure is likely to provide a more secure approach. Here, there are missing spaces for business models beyond traceability-centric values and for the quantification of benefits from IoT in SCM [22].

\subsubsection{Digitalization}

In the last few years, the blockchain technology has been considered one of the technologies that can change the way many industrial sectors and processes operate [11]. Furthermore, the new business model paradigms for blockchain may shift the society toward a digital future [29].

According to Bharadwaj et al. [23], digital transformation is defined as a digital business strategy (DBS), which is 'a fusion between IT strategy and business strategy that creates a fundamental driver of business value creation and capture'. Moreover, Bharadwaj et al. [23] provided the ' 4 S Model', which captures the key attributes of the DBS. This four-theme model can support the development of specific intermediate metrics and criteria for tracking and assessing the digital transformation.

Burkhart et al. [38] explored the relationship between the business model concept and other concepts in the management literature, including business process models and strategies. Business models are the ' $w$ hat' the firm does to create and capture value, whereas business process models focus on the ' $h o w$ ', or rather the day-by-day operationalization and realization of the business model. According to Burkhart et al. [38], the distinctiveness of business models and strategies is less clear, but they remain distinct. According to Osterwalder et al. [39], the distinctiveness of the business model is that it provides the 'missing link' between strategy and tactics. One of the conclusions they draw is that the business model and strategy concepts are related but distinct. Moreover, the business model must be highly focused on the interactions across organizational boundaries, and 
the notion of value is central to its conceptualization. In terms of value capture, the business model is more concerned with the appropriation mechanisms, whereas in the strategy the attention is directed toward threats to returns posed by current and potential entrants. Additionally, according to Osterwalder et al. [39], there is a strong relationship between the business models and the IT instructors applied by the stakeholders of a network.

For a better understanding of the digital transformation, Brown et al. [24] synthesized a framework - the ' $4 E$ Model' - that can be used for an understanding of the maturity and transformational activities inside companies and governments. This model can also support the development of specific intermediate metrics and criteria for tracking and assessing digital transformation. Therefore, these four layers have different approaches and insights that can support the identification of operational clusters to address digital transformation concerns. In this instance, cultural, capability, and leadership improvements must be addressed.

The 4E Model theory is a simple four-layer structure divided into (I) expectationsincluding people, communities, and clients; (II) execution-for organization and delivery; (III) ecosystem-containing data, capabilities, and interfaces; and (IV) enablers-involving infrastructures and technology.

The first layer of the $4 \mathrm{E}$ Model, the expectation, sets the focus on the end customers and into the requirements needed to satisfy needs and acquire feedback. The second layer (execution) considers the impact of digital transformation on behavioral aspects, organizational structures, and decision-making approaches. Brown et al. [24] highlights that a simple implementation of digital technologies over traditional legacy processes and IT practices will not work. Timing is an important factor for this layer. The third layer (ecosystem) puts the focus on the technology components and business rules, whereas the fourth layer (enablers) is oriented to a classification and assessment of those features that may support the digital transformation.

\subsection{Taxonomies of Existing Work}

Conducting this literature review, we identified relevant previous studies and methods. These outcomes support this research, providing valuable approaches for identifying those assets for digitalization, and conveying them toward the identification of those elements to design blockchain-based strategies. Thus, recognizing the elements of IT strategies and business strategies, we can see the impact on how the operational clusters are managed during the digital transition.

Therefore, in this paragraph, a taxonomy is presented as the outcome of the literature review performed. Table 2 shows a classification in four groups of application. However, we recognize the literature review may have some limitations and that we may have not identified all the most relevant research or studies that were published in renowned journals. However, the literature review methodology was performed in a rigorous manner to assure a high level of research findings, and it may represent non-exhaustive research.

Table 2. Taxonomy.

\begin{tabular}{|c|c|c|}
\hline References & Class & Description \\
\hline$[1,4,18,19,25,27]$ & Features & $\begin{array}{l}\text { This cluster collect the benefits, characteristics, and } \\
\text { aspects about the implementation of blockchain in } \\
\text { supply chains }\end{array}$ \\
\hline$[5,7,12,28]$ & Phases & $\begin{array}{l}\text { Several issues and recommendations are grouped } \\
\text { in this class to foster the digital transition in SC, } \\
\text { with and without blockchain }\end{array}$ \\
\hline$[9,21,23,24,26]$ & Digital dimensions & $\begin{array}{l}\text { Digital transformations models and SC } \\
\text { components are gathered in this class }\end{array}$ \\
\hline$[3,8,17,20,22]$ & Risks management & $\begin{array}{l}\text { SC risks, barriers, and mitigation aspects } \\
\text { are collected }\end{array}$ \\
\hline
\end{tabular}




\section{Methodology}

In this section, the research methodology is presented. As an explorative study, qualitative methods as expert interviews were applied. With a specific focus on ethnographic and grounded theory approaches, the selected literature is the following [40-48].

\subsection{Design of the Study}

According to Saberi et al. [3], the grounded theory approach can be used to expand the features of blockchain and its practical implementation. Therefore, following Corbin and Strauss [40], a dynamic approach was designed for this qualitative research. This dynamic approach enables evolution in design as the study progresses [41]. As a form of qualitative research, the grounded theory is used to construct a theory grounded in data [40,42-46]. By identifying general concepts, the development of theoretical explanations offers new insights into the studied phenomena.

This study maintains an investigatory character and lays the foundation for this research area. In accordance with Bogner et al. [47] and Bolger et al. [48], we established flexible guidelines to run this ethnographic research and identified experts with a high degree of interpretive faculty and extensive knowledge in their respective fields.

\subsection{Experts Description}

The pool of experts (Table 3) is composed of academics (AC), information and communication technology professionals working in renowned companies (ICT), and institutional representatives (WO). The international experts are from EU and non-EU countries and possess a proven knowledge of blockchain. In this instance, experts have different backgrounds in academia, private companies, and institutions. They were studying and/or working in blockchain technology from 2014, on average.

Table 3. Pool of experts interviewed.

\begin{tabular}{|c|c|c|c|c|}
\hline$\#$ & Respondent Provenance (Anonymized) & Sector of Interest & Gender & Location \\
\hline 1 & ICT_1_Logistics & Handling & M & Belgium \\
\hline 2 & ICT_2_Consulting & Business models & M & New York \\
\hline 3 & ICT_3_Consulting & Business services & M & Spain \\
\hline 4 & ICT_4_Consulting & Financial flows & M & New York \\
\hline 5 & ICT_5_Telecommunications & Service provider & M & Spain \\
\hline 6 & ICT_6_Technology & Service provider & M & Ireland \\
\hline 7 & ICT_7_Logistics & Software architecture & $\mathrm{F}$ & United Kingdom \\
\hline 8 & ICT_8_Manufacturing & Industrial IoT & M & Italy \\
\hline 9 & AC_1_Social science & Innovation & $\mathrm{F}$ & United Kingdom \\
\hline 10 & AC_2_Social science & Economics & M & Australia \\
\hline 11 & AC_3_Social science & Information flows & $\mathrm{F}$ & United Kingdom \\
\hline 12 & AC_4_Engineering & Network technologies & M & Spain \\
\hline 13 & AC_5_Engineering & Network security & M & Belgium \\
\hline 14 & AC_6_Engineering & Cryptography & $\mathrm{F}$ & Spain \\
\hline 15 & AC_7_ Engineering & Computer science & M & Switzerland \\
\hline 16 & AC_8_Social science & Digital economy & $\mathrm{F}$ & United Kingdom \\
\hline 17 & WO_1_Law and regulation & Policies & M & Belgium \\
\hline 18 & WO_2_Computer-implemented invention & Technicians & M & Germany \\
\hline
\end{tabular}


To select these experts, we conducted networking actions and an exploration about the level of activities performed in the last 5 years, in terms of blockchain, supply chain, digital applications, Industry 4.0, and the interests in managing emerging technologies. Thus, we selected over 20 experts to be contacted. Experts were contacted by structured emails, following a formal format of presentations, connections with their activities, and why we considered their involvement suitable for the study.

Only eight interviews were conducted in person, while the other 10 were conducted virtually using video-conference software. Additionally, classified on the basis of gender, $72 \%$ of the interviewees were male experts, and the remaining $28 \%$ were female (5 out of 18). We tried to assure an equal value in this aspect, but the results were not as good as we hoped.

The balance of their backgrounds varied and were correlated with supply chains and logistics. As presented in Table 3, sectors of interest and expertise were from handling to Industry 4.0, from business services to software architecture, from network security to information flow, as well as financial flows, innovation, and digital economy. All these sectors of interest were relevant for this study, and interviews were conducted by keeping the focus on blockchain-based supply chains and their direct impact with supply chain operations.

\subsection{Data Collected}

Data were collected through memos and notes. The interviews were recorded with prior authorization, and the data collected followed a screening process to develop a narrowed analysis for the study. Although the 18 interviews allowed us to collect a large amount of data, other sources of knowledge were considered in this study.

\subsection{Grounded Theory Assessment}

As an explorative research, we recognize the potential limitations of this study. First, the interviewees' selection process may have overlooked several renowned experts who may have brought additional perspectives in the analysis. Likewise, as a qualitative approach, the data collection and assessment might have been influenced by our personal judgments. However, the grounded theory was applied in a meticulous manner to assure the mitigation of possible misleading outcomes with respect to defined criteria. By conducting the expert interviews, we collected a large variety of results, and the presented results were not fully comprehensive but focused on answering the given RQ.

On the basis of a rigorous application of the grounded theory methodology, we identified the main concepts and categories that emerged from the analysis. While conducting the grounded theory, the analysis was passed over three steps of code iterations, reducing the complexity from 600 to 200 codes, and reducing it further to 50 codes in the second iteration. In the third phase, four categories were identified and analyzed. These four categories are presented in the next section.

\section{Findings}

In this section, the main results of the analysis are presented in a descriptive manner. Each subsection clearly focuses on empirical findings, retaining the explorative character of the research work; all outcomes are provided following a neutral and impartial approach. Experts' views have been collected, analyzed, and summarized in four major categories: (i) benefits, (ii) concerns, (iii) digital transition, and (iv) digital business models.

\subsection{Benefits}

Interviewees have a common vision of the main blockchain benefits for SC applications. Transparency, verifiable processes, immutability, traceability, and paperless procedures are major benefits. By merging these benefits together, we would find an impact on the platforms for providing event automation and combining the distribution processes within the product lifecycle. Interviewees showed consensus about the crucial effect of these 
benefits for food SC operations, their optimization, and trust. Furthermore, a blockchain system is suitable for ecosystem building in food SCs, and it can enable autonomous generation of business ecosystems.

Another common vision of interviewees is the impact of blockchain on business procedures. In this instance, blockchain may change many ways to run operations, support digitalization strategies, play a fundamental role in digital assets, and also design some changes in the traditional methods that people and governments are using to perform.

For accounting and public administration, a blockchain system can impact the IT units with deep restructuring, reduction of intermediaries, and paperless operation. It may be an adaptive change; in fact, interviewees emphasized that blockchain would have the power to change behaviors for administrative tasks. With a sharp focus on purchases and sales business units, digitalization is encouraging a cultural change for SC micro-companies. For instance, considering smart-bids, new paradigms and methods are emerging alongside the development of smart contracts for procurements. Interviewees remarked that this implementation can bring to the market a new concept for business trust maintenance and industrial trust, promoting behavioral and managerial changes in the future industry. Accordingly, administrative tasks become lean and transparent for both companies and governments. New ethical standards may emerge in the community as a result of new negotiation procedures and higher levels of trust, and there will be a cultural change in tax obligations and their related economic aspects. In this field of application, blockchain can mitigate a range of problems related to money laundering, tax transparency, illegal labor, black markets, and illegal international trade. In contrast, interviewees noted how ledger (digital) identity is a beneficial technology feature for addressing administrative needs and mitigating the previously cited problems.

Regarding education, interviewees also explained how blockchain can have a positive impact in this sector. Supporting proof of qualifications, proof of training, and degrees at an international level, new applications in the educational sector may play an important role in the future, improving performance in several infrastructures. In this instance, the European blockchain services infrastructure (EBSI) is developing good pilot applications.

In addition, interviewees also pointed out the financial and banking industry. Financial services may lead to a structural chance in traditional operations, enhancing the performance in both digital and security services. For harmonizing other technologies with blockchain, interviewees explained that blockchain, as a secondary system, must be integrated with running systems to exploit the entire efficiency potential, both regarding performance and energy consumption. This may boost blockchain adoption, support new digitalization strategies for business processes, and exchange value between international financial services. However, interviewees remarked how blockchain adoption takes time, and many regulations are still missing.

\subsection{Concerns}

Interviewees also underscored several risks related to blockchain implementation in SCs. The main concern in SC operations is about the current designed systems; in fact, a blockchain-based system in the SC is a centralized system, which reduces the decentralization capacity.

Furthermore, interviewees have a clear consensus on energy issues for the implementation of these emerging systems. In this instance, blockchain technology might powerfully impact industry applications, but it is not a green technology, and environmental issues need to be considered in advance. Accordingly, innovation and research in this field may help reduce energy consumption and increase performance. However, this would be a responsibility issue for the whole research community that is working on energy-intensive technologies such as blockchain.

Furthermore, common concerns highlighted by interviewees are related to the government, consortiums, share costs, legal implications, new technology lawyers, lack of efficiency, expensive resources, and cost of computational power. In addition to these 
issues, interviewees mentioned the barriers regarding energy questions around the world, the negative impacts of the technology on global warming, the high expectations from potential implementation in the industry, and the concern about possible exit strategies from blockchain data platforms. Other criticisms are more oriented to technical issues and drawbacks such as energy use, low performance (slower than other platforms/systems in use), migration paths, scale-up capability, and other core technology issues.

Interviewees pointed out that, at this stage, blockchain products are data platforms centralized by one or more big companies. This design does not simplify the creation of any value in a chain. Interviewees remarked that blockchain solves only the consortia building process for value chains. In this instance, companies play in a centralized way, deploying platforms as a tool to manage the complexity of stakeholders for international SCs.

Moreover, the common awareness among interviewees is about the infancy and complexity of blockchain. Whereas blockchain does not represent an integrated solution thus far, practitioners are struggling to determine how complex and how big the future blockchain market will be. Even though start-ups would play a fundamental role in blockchain development and innovation, interviewees are skeptical about blockchain applications for small- and medium-sized enterprises (SMEs). This skepticism is related to the adoption of international SCs for multinational companies, where the involved stakeholders would implement the technology to increase a specific operational performance in a wide and complex ecosystem. Thus, in this instance, start-ups would have difficulties finding the right business space. However, interviewees remarked that highly relevant SMEs play in this emerging market. SMEs have agility, dynamism, and openness to boost innovation at a further stage, pushing faster digital transformations and new skills.

\subsection{Digital Transition}

After collecting the statements provided by interviewees, a possible framework of analysis for blockchain digital transition-as an emerging technology—may be designed to compare the capacity to transform a single operation with the number of systems involved in that specific procedure. Additionally, to understand future technology/business directions, it is essential to discover the critical performances that can be exploited with a broader blockchain deployment.

Interviewees agreed that blockchain may support digital transition for SCs and that it creates incremental changes and innovations to existing systems. The digitalization and harmonization within other technologies may generate improvements, sustainability, and effective growth for new practices in SCs. Interviewees remarked that blockchain may represent a driver of digital transformation in businesses. In this instance, the growth rate might be explained as a technology-push but shaped by the market. Conversely, regarding marketing strategies, interviewees pointed out that there are also several market-driven approaches for asset digitalization. Thus, blockchain may become a digital strategy in which new business models will emerge to compete in digital spaces. This may represent a value exchange in virtual environments, where exchanging value in a trustable way is a key feature.

In SCs, stakeholders must communicate and share information in real time in an efficient and effective manner. Interviewees highlighted that blockchain systems may enhance communication and information management in SCs; however, other software technologies must be used or connected to it.

Interviewees underscored that blockchain platforms have remarkable functional approaches to frame information and data, given that blockchain allows for the organization of the logic of what data are collected in distributed databases. This enables the blockchain data platform to become an optimization tool for business operations and to support the value chain in managing data. Thus, a blockchain platform provides a new service for data optimization.

As an example, interviewees pointed out SC event management (SCEM) systems as existing solutions for data sharing in SCs. Although an SCEM system solves the same prob- 
lem as a blockchain, it is quite complex and has some limitations. In contrast, blockchain adds layers to existing technologies and seems easier to deploy with higher flexibility. In this instance, the blockchain adds layers for traceability and transparency by designing incremental features upon existing systems. Therefore, the interviewees remarked that blockchain systems bring incremental changes for SC applications, which result in performance improvements.

Additionally, interviewees identified the identity issue as one of the potential digital enablers that address blockchain in SCs. Digital identity may represent a technological feature where assets, such as people, companies, public entities, machines, means of transport, and objects moving along an SC, can be linked to blockchain systems. Interviewees stated that this aspect could also solve ethical issues running inside international/illegal SCs. Digital identity may be deployed in SCs to prevent fraudulent and illegal SCs, such as those related to trading of wood from illicit deforestation, criminal and slavery mining for minerals, counterfeit food products, and several other contexts of human rights violations and environmental abuses. However, the digital issues - for these above-mentioned contexts-are related to information entry-point gateways and the way in which to set up a safer and secure way to digitalize assets that are entering the chain. In this instance, interviewees remarked that there are several barriers and risks in assuring trust for these kinds of products, and it is extremely difficult to assure product provenance and ethical management for environmental and human rights. However, looking forward to a broad blockchain deployment, some of the current problems may be solved in future/fully transparent blockchain-based SCs.

\subsection{Digital Business Models}

Interviewees highlighted the relevance of industrial smart contract applications. These industrial applications can lead to new levels of performance in operations, enabling new negotiation procedures and generating new business models. Interviewees mentioned the high impacts of some upcoming blockchain-based business models and how they may improve operational efficiency and effectiveness in future digital procedures.

In contrast, the lack of regulations around this area may hamper the smart contract mechanism to work properly, reducing its applicability to the market. However, interviewees stated how smart contracts are powerful for both SCs and manufacturing operations, but they need permissioned systems; otherwise, unexpected risks may emerge. Thus, the interviewees' consensus is that permissioned systems are more eligible for businesses.

Thus, smart contracts are identified by interviewees as powerful computer programs for administrative automation; however, they have certain limitations and need permissioned systems for implementation in business contexts. Coding smart contracts makes it possible to establish business mechanisms in computer logic and ensure a straightforward level of trust in business procedures. Therefore, distributed systems for ecosystem building employ a new degree of trust, where access control and authorization to invite new members are defined from the beginning.

Regarding the bank and financial industry, interviewees pointed out that tokens have the power to modify several operations and business processes, setting new standards for the exchange of digital assets and value. Although cryptocurrencies and initial coin offerings (ICOs) scared practitioners for their financial consequences and degree of speculation, ICOs have shown good results in the past few years. Interviewees positively evaluated these new mechanisms, and highlighted that tokens have the chance to facilitate transactions and change customers' attitudes and behaviors. Furthermore, tokens may support digital business models, opening new markets, new possibilities, new channels, and providing easier access to technological developments and market strategies.

Additionally, the ISO/TC-307 is seen by interviewees as a standard for financial transactions and human interactions. The ISO has impacts on business and society, and for this reason, interviewees remarked that ISO standards are relevant to allow the sharing of value in a standardized way. Other benefits and impacts include the mitigation of ethical 
issues, tax obligations, adoption by enterprise resource planning (ERP) systems in SCs, and decentralized identifiers (DIDs) in digital identity. Therefore, the interviewees pointed out that blockchain standardization might help harmonize different protocols and facilitate interoperability issues. However, for distributed technologies, future standards should be as simple as possible to generate new digital business models, produce lean and agile procedures, and push the technology on the market.

\section{Discussion}

This section discusses the major considerations emerging from this exploratory study. After a discussion of two main use cases emerged from interviewees, the main reflections and results of this analysis are presented, answering to the RQ in an attempt to bridge the gap in the existing body of knowledge. Therefore, collecting the outcomes of the four categories described in the previous section with the literature review performed, we present the elements for a suitable adoption in SC applications. Additionally, a list of recommendations for blockchain transition in SC operations is provided as a collective result.

\subsection{Use Cases from Interviewees: Network and Ripple Effects}

In this section, interviewees' overviews about the differences for both network and ripple effects in blockchain developments are summarized. Considering two examples in logistics, two different cases are provided to explain two different effects (network/ripple) and its impactful processes.

The network effect for blockchain can reduce costs and increase security. As the Internet has taught us, when an increasing number of users are using a technology, the network provides a set of additional utilization benefits. Therefore, the more the users in the web, the more the generation of content, information, and power. Accordingly, in the logistics sector, digital representatives for objects-digital twins-are already deployed in certain digital ecosystems, managing events automation and a higher level of transparency for many applications. In this field, blockchain platforms redistribute and combine value in the value chain. Tokenization for objects - a blockchain-based digital representativecorresponds to the lot management concept. If a predefined number of tokens are created in line with lot production, each lot has a clear digital representative and, due to cutting-edge SC platforms, the lot can be tracked and traced during the SC distribution. Thus, if the number of tokens is equal to the number of products, the tokens will be used to combat counterfeiting of products. This application may be deployed for high-value products and assure product identity and originality. Due to the network effect, this kind of application may bring social benefits and behavioral changes correlated with a higher level of trust and higher production transparency.

Ripple effect is easier to identify at the first stage of development for blockchain business communities. When a big market player—such as IBM-Maersk's project (tradelens. com) - decides to deploy a new technology, it forces stakeholders involved in the business ecosystem to apply the same technology too. The ripple effect for blockchain businesses started with big companies and consortiums, deploying the initial blockchain tests, and this development appears discontinuously in groups or swarms. Consequently, it may be compared to information flows along a SC. When a big market player deploys a new technology system to manage information, this impact has a ripple effect along the chain of stakeholders involved (manufacturers, insurance companies, institutions and governing bodies, financial societies, and last-mile logistics companies) and they need to align their communication and information platforms within the big player's standards. 
5.2. Which Are the Elements for Designing Blockchain-Based Digital Strategies That Might Foster a Reliable Re-Engineering in SC Operations?

According to the literature reviewed and experts' concepts, blockchain is still in its infancy for prompt adoption in SC operations. However, blockchain presents powerful features for addressing the future evolution and digitalization of SCs.

The adoption pathway needs to be carefully assessed, and an intense commitment is required to design proper functionalities and exploit blockchain benefits.

Therefore, it is fundamental to identify the value creation and capture that blockchain may bring upon existing operations. Blockchain deployment must be supported by digital strategies to identify improvements in trust (for stakeholders) and automation (for operations). In this instance, by addressing the results of expert interviews, traceability, and transparency are key characteristics that should be evaluated for deployment. However, it will be relevant to analyze the processes and data that can be publicly available to stakeholders in the business ecosystem. This increases the level of trust and can support the detection of procedures where tokens and/or smart contracts generate value for critical performance. Moreover, this requires a reengineering of operations with blockchain functionalities, and it must be focused on exploiting the critical performance of traditional processes. To discover business operations where blockchain brings value, research may center digital strategies on single operations, scaling down the complexity and supporting a continuous incremental improvement.

To support the above-mentioned issues, Table 4 provides a matrix tool for placing the first steps of the evaluations. Thus, following Cole et al. [18], Ganeriwalla et al. [49], and Brown et al. [24], we adapted an assessment matrix to this study. Addressing the value of trust and the value of automation from [18,49], we adopted an additional level from the $4 E$ Model from Brown et al. described by [24]. Trust aligns the expectations where people, communities, and clients are involved, whereas automation is involved in the execution for the organization and delivery. As an outcome, the four quadrants were adapted to this scope in Table 4 (traditional/existing systems, explore other technologies, niche application, and blockchain makes sense).

Table 4. Value of trust and automation matrix for blockchain (adapted from $[18,24,49]$ ).

\begin{tabular}{|c|c|c|}
\hline \multirow{3}{*}{$\begin{array}{c}+ \\
\text { Value of automation } \\
\text { (execution) } \\
-\end{array}$} & Explore other technologies & Blockchain makes sense \\
\hline & Traditional/existing systems & Niche application \\
\hline & \multicolumn{2}{|c|}{$\begin{array}{l}\text { Value of trust } \\
\text { (expectations) }\end{array}$} \\
\hline
\end{tabular}

In addition, for blockchain deployment, it is fundamental to recognize the technological levels of the ecosystem where blockchain will be developed. In this instance, it is necessary to evaluate the internal technology level and identify technologies that can be interconnected with blockchain. In a complementary manner, the required external technologies must also be identified, understanding if they will be core-and hence, an own investment is needed — or if they will be secondary technological solutions that may be externalized in outsourcing.

For the integration between blockchain and SC processes, the logic of a distributed data-platform must be defined to avoid excessive computational power consumption. It is relevant to have a sharpening focus on single operations, their interactions, and optimization.

For technology management, risk analysis will be a key asset in understanding the possible negative consequences and harmful impacts for other business units.

At this stage, it is fundamental to consider and carefully assess a performance comparison with other existing technologies or technological solutions. Exploring alternative technological solutions may help organizations mitigate the risks of adoption. Higher risk may result in an excessive effort without receiving real benefits from it. Additionally, blockchain will generate radical changes in other business processes and the way they are accomplished. Thus, a blockchain development plan must be supported by the top man- 
agement, and an accurate change management plan is required in organizations. Change management should be introduced into digital strategies.

For the abovementioned challenges, it would be relevant to assess the transformative role blockchain may have in operations. Therefore, Table 5 was designed in accordance with Pérez [50], Brown et al. [24], and Wang et al. [15]. Addressing the capacity to transform with the number of involved systems from [50], we adopted an additional level from the $4 E$ Model described by [24].

Table 5. Transformative role matrix for blockchain-based operations (adapted from $[15,24,50]$ ).

\begin{tabular}{c|c|c|}
\hline \multirow{2}{*}{$\begin{array}{c}\text { Capacity to transform } \\
\text { (ecosystem) } \\
-\end{array}$} & Connecting & $\begin{array}{c}\text { Exploration } \\
\text { (capitalizing) }\end{array}$ \\
\cline { 2 - 3 } & Collaborating & $\begin{array}{c}\text { Exploitation } \\
\text { (capitalizing) }\end{array}$ \\
\cline { 2 - 3 } & \multicolumn{2}{|c|}{$\begin{array}{c}\text { Involved systems } \\
\text { (enablers) }\end{array}$} \\
\hline
\end{tabular}

The capacity to transform refers to the business ecosystem where platforms and interfaces will be deployed, whereas the number of involved systems refers to the internal/external enablers, such as infrastructures and technologies, that blockchain needs. According to Wang et al. [15], transformative roles were addressed in the four quadrants of Table 5, as follows: collaborating, connecting, exploitation (capitalizing), and exploration (capitalizing).

Furthermore, according to the interviews and literature review, blockchain is an energy-intensive technology and has high environmental impacts. These negative environmental impacts must be considered during development.

Assessing the environmental consequences of blockchain deployment will support a clear identification of environmental targets and good practices. It is necessary to recognize that blockchain solutions should be implemented only if strictly necessary in operations and only if their benefits are measurable.

With respect to sustainable development, it will be crucial to establish the logics and methods of blockchain platforms that will be able to assure ethical behaviors with respect to human and environmental rights. Corporate liability must also be addressed by this asset.

Moreover, the digital strategy must assure trust and avoid centralized systems. In this respect, for acquiring data from a blockchain-based SC, the information gatekeepers must be carefully designed, certifying the entry points and providing an additional level of trust in the evidence (or events) that create the distributed ledger. For this purpose, identifying the right DBS is a key aspect.

To encourage the DBS identification, we adapted a matrix from Lambert et al. [51] and Bharadwaj et al. [23]. Table 6 compares the supply risk with the potential to add value in SC operations [51], framing the business objectives by segments where a DBS may be applied. Thus, in accordance with [23], the $4 S$ Model was adopted within this segment to exploit the more suitable digital strategy per business objective. As an outcome, Table 6 provides four quadrants to address the blockchain-based DBS that might foster a reliable re-design in the SC, as follows: speed (efficiency), scope (effectiveness), scale (profitability), and source (robustness).

Table 6. Digital business strategy identification matrix (adapted from [23,51]).

\begin{tabular}{|c|c|c|}
\hline \multirow{3}{*}{$\begin{array}{c}+ \\
\text { Supply risk } \\
-\end{array}$} & $\begin{array}{c}\text { Scope (effectiveness) } \\
\text { Supply quality and continuity }\end{array}$ & $\begin{array}{c}\text { Source (robustness) } \\
\text { Profitable long-term growth for parties }\end{array}$ \\
\hline & $\begin{array}{c}\text { Speed (time) } \\
\text { Simplicity and efficiency }\end{array}$ & $\begin{array}{c}\text { Scale (profitability) } \\
\text { Cost savings and value maximization }\end{array}$ \\
\hline & - & to add value \\
\hline
\end{tabular}




\subsection{Recommendations for Re-Engineering of SC Operations}

In this section, merging the outcomes from the taxonomy and the results from the expert interviews, we present an additional contribution. Thus, a list of recommendations is provided in an attempt to bridge the gap in the existing body of knowledge.

Summarizing the considerations described in the previous section (RQ), we have framed the results in four steps recognized from the taxonomy: (1) identify, (2) assess, (3) design, and (4) assure. As presented in Table 7, this framework is composed of 22 statements that support both evaluations and detections of relevant aspects to be considered during blockchain adoption in SCs. Therefore, all contributions presented in this section are proposed as a guidance for blockchain-based digital transition in SC applications.

Table 7. Four steps framework for the evaluation and detection of relevant aspects.

\begin{tabular}{|c|c|}
\hline \multicolumn{2}{|r|}{ IDENTIFY } \\
\hline 1 & business operations where blockchain brings value \\
\hline 2 & which processes/data can be publicly available \\
\hline 3 & which internal technologies can/must be linked with blockchain \\
\hline 4 & which external technology can/must be acquired (outsourcing or investments) \\
\hline 5 & digital strategies for creation and capture of value \\
\hline 6 & operations where tokens and/or smart contracts generate value on critical performances \\
\hline 7 & digital strategies for single operations, scaling down complexity for continuous incremental improvement \\
\hline 8 & alternative technological solution to mitigate risks \\
\hline \multicolumn{2}{|r|}{ ASSESS } \\
\hline 9 & how to exploit critical process performances \\
\hline 10 & performance comparisons with other technology solutions \\
\hline 11 & (carefully) the change management \\
\hline 12 & the internal technology level for a blockchain adoption \\
\hline 13 & environmental impacts of a blockchain development \\
\hline 14 & the added value and value capture of blockchain-based operations (reengineering) \\
\hline \multicolumn{2}{|r|}{ DESIGN } \\
\hline 15 & new procedures and processes for blockchain deployment \\
\hline 16 & integrations with internal processes and technologies \\
\hline 17 & the data platform logic for the optimization in single operations \\
\hline 18 & (carefully) information gatekeepers, otherwise trust is not assured \\
\hline \multicolumn{2}{|r|}{ ASSURE } \\
\hline 19 & avoid centralized systems \\
\hline 20 & deploy blockchain solutions only if strictly necessary \\
\hline 21 & carry out a risk analysis for the implementation \\
\hline 22 & $\begin{array}{c}\text { establish appropriate blockchain logics and methods that guarantee ethical behaviors with respect to human and } \\
\text { environmental rights }\end{array}$ \\
\hline
\end{tabular}

\section{Conclusions}

In this study, experts' opinions on blockchain-based SCs were explored. Using an explorative research approach, we conducted 18 interviews with international experts from different countries. Applying the grounded theory methodology, we analyzed the collected data and identified four categories.

This study lays the foundation for the development of digital business strategies in blockchain-based SCs and ensures a reliable redesign of those SC operations that can guarantee efficiency and effectiveness for future deployments. As major outcomes, this explorative research provides a set of matrices and a reference framework that can support the recognition of innovative pathways in this area of application.

Additionally, other research insights may be explored and connected with these presented results. To enhance future investigations, future studies may be performed, 
designing quantitative approaches (i.e., [52]) and merging these two different perspectives, generating comprehensive results.

Author Contributions: F.D.V. was conducting the study and analysis; M.O. was supervising the whole activities. Both authors have read and agreed to the published version of the manuscript.

Funding: This work was supported by the Generalitat de Catalunya, grant no. 2017-SGR-1739.

Institutional Review Board Statement: Not applicable.

Informed Consent Statement: Not applicable.

Acknowledgments: The authors are pleased about the outcomes achieved in this explorative research and would like to thank the pool of experts interviewed for their kind collaboration and time. The expertise provided helped enrich the body of knowledge about blockchain technology and its deployment in SC.

Conflicts of Interest: The authors declare no conflict of interest.

\section{References}

1. Chang, Y.; Iakovou, E.; Shi, W. Blockchain in Global Supply Chains and Cross Border Trade: A Critical Synthesis of the State-of-the-Art, Challenges and Opportunities. Int. J. Prod. Res. 2020, 58, 2082-2099. [CrossRef]

2. Pournader, M.; Shi, Y.; Seuring, S.; Koh, S.L. Blockchain Applications in Supply Chains, Transport and Logistics: A Systematic Review of the Literature. Int. J. Prod. Res. 2019, 58, 2063-2081. [CrossRef]

3. Saberi, S.; Kouhizadeh, M.; Sarkis, J.; Shen, L. Blockchain Technology and Its Relationships to Sustainable Supply Chain Management. Int. J. Prod. Res. 2019, 57, 2117-2135. [CrossRef]

4. Kayikci, Y.; Subramanian, N.; Dora, M.; Bhatia, M.S. Food Supply Chain in the Era of Industry 4.0: Blockchain Technology Implementation Opportunities and Impediments from the Perspective of People, Process, Performance, and Technology. Prod. Plan. Control 2020. Available online: https:/ / www.tandfonline.com/action/showCitFormats?doi=10.1080/09537287.2020.181075 7 (accessed on 25 June 2020). [CrossRef]

5. Wamba, S.F.; Queiroz, M.M. Industry 4.0 and the Supply Chain Digitalisation: A Blockchain Diffusion Perspective. Prod. Plan. Control 2020. [CrossRef]

6. Saberi, S.; Kouhizadeh, M.; Sarkis, J. Blockchains and the Supply Chain: Findings from a Broad Study of Practitioners. IEEE Eng. Manag. Rev. 2019, 47, 95-103. [CrossRef]

7. Bai, C.; Sarkis, J. A Supply Chain Transparency and Sustainability Technology Appraisal Model for Blockchain Technology. Int. J. Prod. Res. 2020, 58, 2142-2162. [CrossRef]

8. Hastig, G.M.; Sodhi, M.S. Blockchain for Supply Chain Traceability: Business Requirements and Critical Success Factors. Prod. Oper. Manag. 2019, 29, 935-954. [CrossRef]

9. Kittipanya-Ngam, P.; Tan, K.H. A Framework for Food Supply Chain Digitalization: Lessons from Thailand. Prod. Plan. Control 2019, 31, 158-172. [CrossRef]

10. Courcelas, L.; Lyons, T.; Ken, T. Conclusions and Reflections; The European Union Blockchain Observatory and Forum 2018-2020. 2020. Available online: https://www.eublockchainforum.eu/sites/default/files/reports/report_conclusion_book_v1.0.pdf (accessed on 25 June 2020).

11. Della Valle, F.; Oliver, M. Blockchain Enablers for Supply Chains: How to Boost Implementation in Industry. IEEE Access 2020, 8 , 209699-209716. [CrossRef]

12. Seyedghorban, Z.; Tahernejad, H.; Meriton, R.; Graham, G. Supply Chain Digitalization: Past, Present and Future. Prod. Plan. Control 2020, 31, 96-114. [CrossRef]

13. Della Valle, F.; Oliver, M. Blockchain-Based Information Management for Supply Chain Platforms. Int. J. Prod. Res. 2021. under review.

14. Kshetri, N. 1 Blockchain's Roles in Meeting Key Supply Chain Management Objectives. Int. J. Inf. Manag. 2018, 39, 80-89. [CrossRef]

15. Wang, Y.; Sarkis, J. Emerging Digitalisation Technologies in Freight Transport and Logistics: Current Trends and Future Directions. Transp. Res. Part E Logist. Transp. Rev. 2021, 148, 102291. [CrossRef]

16. Kitchenham, B. Procedures for Performing Systematic Reviews; Keele University: Keele, UK, 2004; pp. 1-26.

17. Kouhizadeh, M.; Saberi, S.; Sarkis, J. Blockchain Technology and the Sustainable Supply Chain: Theoretically Exploring Adoption Barriers. Int. J. Prod. Econ. 2021, 231, 107831. [CrossRef]

18. Cole, R.; Stevenson, M.; Aitken, J. Blockchain Technology: Implications for Operations and Supply Chain Management. Supply Chain Manag. Int. J. 2019, 24, 469-483. [CrossRef]

19. Babich, V.; Hilary, G. OM Forum-Distributed Ledgers and Operations: What Operations Management Researchers Should Know about Blockchain Technology. Manuf. Serv. Oper. Manag. 2020, 22, 223-240. [CrossRef] 
20. Ho, W.; Zheng, T.; Yildiz, H.; Talluri, S. Supply Chain Risk Management: A Literature Review. Int. J. Prod. Res. 2015, 53, 5031-5069. [CrossRef]

21. Büyüközkan, G.; Göçer, F. Digital Supply Chain: Literature Review and a Proposed Framework for Future Research. Comput. Ind. 2018, 97, 157-177. [CrossRef]

22. Birkel, H.S.; Hartmann, E. Impact of IoT Challenges and Risks for SCM. Supply Chain Manag. Int. J. 2019, 24, 39-61. [CrossRef]

23. Bharadwaj, A.; El Sawy, O.A.; Pavlou, P.A.; Venkatraman, N. Digital Business Strategy: Toward a Next Generation of Insights. MIS Q. 2013, 37, 471-482. [CrossRef]

24. Brown, A.; Fishenden, J.; Thompson, M. Digitizing Government; Palgrave MacMillan: London, UK, 2014.

25. Nandi, M.L.; Nandi, S.; Moya, H.; Kaynak, H. Blockchain Technology-Enabled Supply Chain Systems and Supply Chain Performance: A Resource-Based View. Supply Chain Manag. Int. J. 2020, 25, 841-862. [CrossRef]

26. WEF. Transformation Map for Blockchain. World Economic Forum. 2021. Available online: https://intelligence.weforum.org/ topics / a1Gb00000038qmPEAQ?tab=publications (accessed on 26 February 2021).

27. Wamba, S.F.; Kamdjoug, J.R.K.; Bawack, R.E.; Keogh, J.G. Blockchain and Fintech: A Systematic Review and Case Studies in the Supply Chain. Prod. Plan. Control 2020, 31, 115-142. [CrossRef]

28. Wang, Y.; Chen, C.H.; Zghari-Sales, A. Designing a Blockchain Enabled Supply Chain. Int. J. Prod. Res. 2021, 59, 1450-1475. [CrossRef]

29. Koh, L.; Dolgui, A.; Sarkis, J. Blockchain in Transport and Logistics-Paradigms and Transitions. Int. J. Prod. Res. 2020, 58, 2054-2062. [CrossRef]

30. Aste, T.; Tasca, P.; DiMatteo, T. Blockchain Technologies: The Foreseeable Impact on Society and Industry. Computer 2017, 50, 18-28. [CrossRef]

31. Leng, K.; Bi, Y.; Jing, L.; Fu, H.-C.; Van Nieuwenhuyse, I. Research on Agricultural Supply Chain System with Double Chain Architecture Based on Blockchain Technology. Futur. Gener. Comput. Syst. 2018, 86, 641-649. [CrossRef]

32. Esmaeilian, B.; Sarkis, J.; Lewis, K.; Behdad, S. Blockchain for the Future of Sustainable Supply Chain Management in Industry 4.0. Resour. Conserv. Recycl. 2020, 163, 105064. [CrossRef]

33. Pólvora, A.; Nascimento, S.; Lourenço, J.S.; Scapolo, F. Blockchain for Industrial Transformations: A Forward-Looking Approach with Multi-Stakeholder Engagement for Policy Advice. Technol. Forecast. Soc. Chang. 2020, 157, 120091. [CrossRef]

34. Reina, A. Robot Teams Stay Safe with Blockchains. Nat. Mach. Intell. 2020, 2, 240-241. [CrossRef]

35. Ivanov, D.; Dolgui, A.; Sokolov, B.; Ivanova, M. Literature Review on Disruption Recovery in the Supply Chain. Int. J. Prod. Res. 2017, 55, 6158-6174. [CrossRef]

36. Ben-Daya, M.; Hassini, E.; Bahroun, Z. Internet of Things and Supply Chain Management: A Literature Review. Int. J. Prod. Res. 2017, 57, 4719-4742. [CrossRef]

37. Kshetri, N. Can Blockchain Strengthen the Internet of Things. IT Prof. 2017, 19, 68-72. [CrossRef]

38. Burkhart, T.; Krumeich, J.; Werth, D.; Loos, P. Analyzing the Business Model Concept-A Comprehensive Classification of Literature. In Proceedings of the ICIS 2011, Shanghai, China, 4-7 December 2011; Volume 12. Available online: https: / / aisel.aisnet.org/icis2011/proceedings/generaltopics/12 (accessed on 31 January 2019).

39. Osterwalder, A.; Pigneur, Y.; Tucci, C.L. Clarifying Business Models: Origins, Present, and Future of the Concept. Commun. Assoc. Inf. Syst. 2005, 2005. 16, 1. [CrossRef]

40. Corbin, J.; Strauss, A. Basics of Qualitative Research: Techniques and Procedures for Developing Grounded Theory; Sage Publications: Newbury Park, CA, USA, 2014.

41. O'Reilly, K. Ethnographic Methods; Routledge: Oxfordshire, UK, 2012.

42. Glaser, B.G.; Strauss, A. Discovery of Grounded Theory: Strategies for Qualitative Research; Routledge: Oxfordshire, UK, 2017.

43. Strauss, A.; Corbin, J. Grounded Theory Methodology. In Handbook of Qualitative Research; Denzin, N.K., Lincoln, Y.S., Eds.; Sage Publications: Thousand Oaks, CA, USA, 1994; pp. 273-285.

44. Locke, K. Rewriting the Discovery of Grounded Theory after 25 Years. J. Manag. Inq. 1996, 5, 239-245. [CrossRef]

45. Suddaby, R. From the Editors: What Grounded Theory Is Not. Acad. Manag. J. 2006, 49, 633-642. [CrossRef]

46. Charmaz, K. Constructing Grounded Theory: A Practical Guide through Qualitative Analysis; Sage Publications: Newbury Park, CA, USA, 2006.

47. Bogner, A.; Littig, B.; Menz, W. Interviewing Experts; Springer: Berlin/Heidelberg, Germany, 2009.

48. Bolger, F.; Wright, G. Use of Expert Knowledge to Anticipate the Future: Issues, Analysis and Directions. Int. J. Forecast. 2017, 33, 230-243. [CrossRef]

49. Ganeriwalla, A.; Casey, M.; Shrikrishna, P.; Bender, J.P.; Gstettner, S. Does Your Supply Chain Need a Blockchain? The Boston Consulting Group. Available online: https:/ /image-src.bcg.com/Images/BCG-Does-Your-Supply-Chain-Need-a-BlockchainMar-2018_tcm81-187053.pdf (accessed on 4 February 2021).

50. Pérez, C. Technological Revolutions and Techno-Economic Paradigms. Camb. J. Econ. 2009, 34, 185-202. [CrossRef]

51. Lambert, D.M.; Schwieterman, M.A. Supplier Relationship Management as a Macro Business Process. Supply Chain Manag. Int. J. 2012, 17, 337-352. [CrossRef]

52. Wu, H.; Cao, J.; Yang, Y.; Tung, C.L.; Jiang, S.; Tang, B.; Liu, Y.; Wang, X.; Deng, Y. Data management in supply chain using blockchain: Challenges and a case study. In Proceedings of the 28th International Conference on Computer Communication and Networks (ICCCN), Valencia, Spain, 29 July-1 August 2019; pp. 1-8. 


\section{Short Biography of Authors}

Fabio Della Valle is pursuing a Ph.D. with University Pompeu Fabra, Barcelona, Spain. In the engineering department, he is conducting research on blockchain technology and IoT systems for supply chains. He obtained an MSc in Industrial Engineering and Management at the University of Pisa and worked more than five years in different technology transfer offices in Europe. He has worked on the exploitation of research, innovation management, IP rights, entrepreneurship education and supporting academic-based start-ups during business growth. Fabio started his first investigation on blockchain technology and DLTs in 2015 at the Centre for the Digital Economy at University of Surrey.

Miquel Oliver is a Full Professor at the Department of Information and Communication Technologies of the University Pompeu Fabra. He received his Ph.D. from Universitat Politècnica de Catalunya in 1999, a degree in Business Administration (UOC, 2009) and GloColl Executive Education (Harvard, 2011-2012). Before joining UPF, he was an Associate Professor at the UPC and a Visiting Scholar at Rutgers University (US, 1999). He has led the multidisciplinary Networking and Strategies Research Group (NeTS) since its foundation. He has been a Visiting Scholar at Cardiff University (2019), Southampton (2018), MIT (2013-14), and Columbia University (2011). His research involves wireless communications, with a multidisciplinary view including regulation, telecom policies, and economic impact. 